\title{
Does Mandatory Pressure Increase RFID Adoption? A Case Study of Western Australian Livestock Industry
}

\author{
Mohammad Alamgir Hossain ${ }^{1, *}$ and Mohammed Quaddus ${ }^{2}$ \\ ${ }^{1}$ School of Business, North South University, Dhaka, Bangladesh \\ mahripon@yahoo.com \\ ${ }^{2}$ Graduate School of Business, Curtin University of Technology, Western Australia \\ Mohammed.quaddus@gsb.curtin.edu.au
}

\begin{abstract}
Radio Frequency Identification (RFID) technology has been increasingly used in innovative applications around the world. It has caught attention of different industries and been mandated by resource dominant organizations and different countries in various applications. In Australia RFID is mandatory for cattle identification. The objective of this research is to investigate whether the mandatory pressure really makes the livestock farms to adopt RFID. This study took the broader aspect of external environment considering external pressure, external support, and external uncertainty. Applying a mixed method approach this is a prime initiative exploring and detailing the external environmental factors on RFID context. Following extensive literature on innovation and RFID adoption this paper, first, explores the relevant factors on miscellaneous innovations. The literature review was followed by a qualitative field study. The field study confirms and contextualizes the factors from the literature review. Finally, an empirical study investigates the adoption behavior of livestock farms in relation to RFID adoption in the context of Western Australia. Data were analyzed using Partial Least Square (PLS)-based Structured Equation Modeling (SEM) tool. The analysis finds that market pressure, cognitive pressure, government support, and external uncertainty are the main driving factors in RFID adoption. Implications of the results are highlighted.
\end{abstract}

Keywords: RFID, adoption, external environment, mixed method, PLS.

\section{Introduction}

Radio frequency identification (RFID) is one of the most effective technologies which identifies an object automatically and uniquely, and can store enormous amount of data for many years which can later be retrieved as information as required (Hossain and Quaddus 2011). Because of its enormous capabilities RFID enjoys a quick growth in recent decades in many innovative applications around the world and has drawn the attention of the innovation architects and researchers. Now-a-days, RFID technology

\footnotetext{
* Corresponding author.
} 
is used extensively from item-level tracking through the supply chain to fault monitoring in train tracks to electronic passports.

The revolution of RFID has not started before it was mandated by several key players of the external environment. In 2003 Wal-Mart and Department of Defense (DoD) of United States Stores mandated their suppliers to attach RFID tags at case/palette level (Bansal 2003; Jones et al. 2005; Roberti 2003; Whitaker et al. 2007). Around the same time Tesco, Metro AG, Target, and Albertsons issued guidelines for their suppliers to be RFID enabled (Poirier and McCollum 2006; Garry 2004). In livestock industry, the first significant external pressure was introduced by European Union (EU), in late 1990 (Semple 2007), which was followed by Japan, South Korea, and United States. A considerable amount of consumer awareness is also observed which increases with time and eventually is converted to a demand for a precise method of meat traceability. As not every farmer has "the same enthusiasm and urgency for incorporating RFID technology" (Nolz 2008), to entertain the consumers' demand, livestock agencies and organizations put pressure on the producers for the traceability information.

Hence, it is observed that the external environment plays a significant role on RFID adoption. Though a number of studies have been found which dealt with the effect of environmental, technological, and organizational (TOE) characteristics on RFID adoption but surprisingly, to the best of authors' knowledge, no study has been conducted detailing the external environment in RFID context; though external environment is regarded as the most influential factor for RFID adoption. Generally, there are only a handful of researches on the overall uptake of RFID in livestock sector though there is a significant body of research in logistics area. This paper thus takes the opportunity to study RFID adoption, in addressing the current literature gap, by exploring and examining the external environmental factors on RFID, taking Western Australian (WA) livestock industry as the context. Equipped with a background of environmental factors for RFID adoption, this paper performs an exploratory field study on eight livestock farms in WA, develops an initial research-model which is validated further with quantitative data to examine and identify the environmental factors affecting RFID adoption.

This paper is organized as follows. The next section presents the literature review and the theoretical grounds of external environmental issues on RFID adoption which is followed by presenting the research methodology, and then discusses the findings of the qualitative field study while developing the propositions. The following sections present and discuss the results from a quantitative survey. This paper ends with conclusion and further work sections.

\section{Background}

Scott (2001) indicates that, in order to survive, organizations must conform to the rules and demands prevailing in the environment. In other words, organizations' adoption decisions aim primarily at organizational achievements; however, the decisions sometimes are directly influenced by the external business-environments. Similarly, Social Cognitive Theory (SCT) argues that organizational factors regarding innovation are necessary but not sufficient (Bandura 2001); the process includes environmental effects 
including the pressure of social influence and incentives. SCT also recognizes that gaining social recognition and status are the main motivations for adopting an innovation which is termed as 'normative pressure' in the institutional theory. Institutional theory assumes that organizations cannot operate in isolation rather they need to respect and follow the trends and demands of the external environment where they operate. Institutional theories define the environment as an integrated set of political, economic, social, and legal conventions that establish the foundational of a productive business environment (Oxley 1999). It is agreed that institutional environment is a very important external factor to firms. Institutional theory, thus, emphasizes on institutional environments in organizational strategy, policy, and operations (Scott 2001). Moreover, firms usually do observe each other over time to gain competitive advantage and also to respond to the competitive pressure and market pressure (Gibbs and Kraemer 2004). In recent time Teo et al. (2003) applied the institutional theory to examine intention to adopt interorganizational linkages; especially financial electronic data interchange (FEDI). Moreover, proactively, Gibbs and Kraemer (2004) applied institutional theory in conjecture with the Technology-Organization-Environment (TOE) framework, proposed by Tornatzky and Fleischer (1990).

Moberg et al. (2002) classified the adoption factors into environmental, organizational, and informational factors. To explore the adoption factors at organization-level and to study the adoption of technological innovations, Tornatzky and Fleischer (1990) proposed the Technology-Organization-Environment (TOE) model. TOE argues that the decision to adopt a technological innovation is based on factors in the organizational and environmental contexts, as well as the characteristics of the technology itself. However, the detail nature of external environment is somewhat missing in TOE studies. In investigating the external factors on RFID adoption, this study used the "environment" construct from TOE model. A similar type of study was performed by Teo et al. (2003).

\subsection{External Environment}

The external environment consists of those relevant factors outside the boundaries of the organization (or a specific decision unit) that are taken direct into consideration. External environment, therefore, consists the 'global' external factors which are beyond organization's control but are important in functioning and decision-making behavior (Quaddus and Hofmeyer 2007).

Numerous innovation studies have examined a variety of external environmental factors, including economic conditions, global competitiveness, transaction climate, industry concentration, and environmental uncertainty on decision to adopt new technologies (Gatignon and Robertson 1989; Quaddus and Hofmeyer 2007). In general, external environment has been recognized to play a very significant role in adoption diffusion research and so as for RFID adoption (Sharma and Citurs 2005; Wen et al. 2009). Based on literature external pressure, external support, and external environmental uncertainty are viewed as important environmental factors for RFID adoption (Hossain and Quaddus 2011).

\subsubsection{External Pressure}

External pressure has been considered as a significant factor in adoption research (Gatignon and Robertson 1989); not surprisingly is also treated similarly for RFID 
adoption (Matta and Moberg 2007; Schmitt and Michahelles 2009). External pressure can be exercised by different authorities as follows:

Government Pressure: Government pressure or "regulative process" (Lawrence et al. 2001 ) is a kind of coercive pressure as government exercises its power to force the targeted people or industry in order to gain compliance to a desired system or practice. Government regulation can either encourage or discourage the adoption of innovation (Scupola 2003). Shih et al. (2008) considered government policy/legislation as one of the leading challenges for RFID adoption. More specifically, Luo et al. (2007) argued that government mandate can speed up the rate of RFID adoption.

Market Pressure: An ultimate reason to adopt RFID by livestock industry is the increasing market pressure and mandates by supply chain partners for RFID-based animal tracking systems ( $\mathrm{Li}$ and Visich 2006; Schmitt and Michahelles 2009). Meat exporting agents follow the pressure of the market and impose it to the meat producers. Therefore, imposition from trading partners makes the livestock producers to adopt RFID because they are the most susceptible to such imposition. Such impositions are prevalent in case of RFID because of its network nature, like EDI (Iacovou et al. 1995).

Competitive Pressure: Larger retailers and also small farms keenly aware of what competitors are doing, with respect to new IT tools or technology that may provide competitive advantage (Brown and Russell 2007). One of the main sources of external pressure to adopt RFID is the pressure due to fierce competition (Iacovou et al. 1995). As more countries and competitors are becoming RFID-enabled, livestock farms in Australia are more inclined to adopt RFID in order to maintain their own competitive pressure, though Brown and Russell (2007) did not find so in retail sector.

Mimetic Pressure: "Mimetic pressure involves the perception of some value of mimicking a behavior from other referent actors" (Lawrence et al. 2001, p. 628). Mimetic pressure is exerted on an organization by itself when the organization perceives that another organization on the same business environment are getting benefit of an innovation or practice and thus feels the pressure to act on a same manner (Teo et al. 2003). This is a "cognitive process" (Lawrence et al. 2001). Sharma et al. (2007) suggests that mimetic pressure is positively and significantly related to RFID adoption.

Normative Pressure: Organizations may experience the normative pressure sharing the similar norms in a given environment; to be treated differently or to receive respect from the other members of the society such as the other farmers and supply chain partners. An organization with a direct or indirect relation to other organizations that have adopted an innovation may get interest to the innovation and finally adopt the innovation to gain the similar social recognition and benefits (Teo et al. 2003; Lawrence et al. 2001).

\subsubsection{External Support}

External support for relevant technology is considered as an important factor that matters to potential adopters (Huyskens and Loebbecke 2007). External support can have different sources varying from country to country and from region to region within a same country. External supports can be provided by the government, technology vendors and change agents. 
Government Support: Government is an important environmental actor for RFID adoption (Lin and Ho 2009). Government can play an important role for an RFID adoption-diffusion through restructuring the infrastructure, information provision, research and development policies, providing incentives, building and enhancing the infrastructure, conducting pilot projects, provision of tax-breaks, and providing consultancy and counseling service (Lin 2009; Lin and Ho 2009; Luo et al. 2007). In fact, without government action and intervention it is treated by the individual adopters as a "risky" investment that demands a 'risk-share' by the government.

Vendor Support: Supports from technology providers (Huyskens and Loebbecke 2007 ) is also very important as many organizations may not have the internal expertise to trial and implement RFID projects, and would therefore rely on external providers (Lee and Shim 2007). Vendors may support the potential and already-adopters by providing training, incentives, discounted products, trial use, customized solutions, troubleshooting services, and conducting pilot projects. The availability of vendor supports may vary from place to places and have a significant influence on RFID adoption (Brown and Russell 2007).

\subsubsection{Environmental Uncertainty}

Uncertainty originates from lack of information, know-how, or the ability to predict developments and situations (Rogers 1995). Environmental uncertainty would influence the innovation adoption. Zhu et al. (2003) and Lee and Shim (2007) argued that market uncertainty is important to help understanding RFID adoption because organizations usually pay more attention on innovations when they face an environment with higher instability and chaos (Gatignon and Robertson 1989; Kimberly and Evanisko 1981; Patterson et al. 2003). Alternatively, uncertainty about the innovation itself may hinder the adoption process because organizations do not adopt an innovation if there is not a significant level of assurance of the utility of the innovation. On other words, uncertainty about RFID itself, and the future market and return negatively influence the adoption of RFID (Hossain and Quaddus 2011).

\section{Methodology}

To understand the research topic, to validate and understand the conceptual model, and to obtain and analyze data a combination of both qualitative and quantitative methods, which is referred to as the 'mixed method' (Tashakkori and Teddlie 1998), was applied in this study. A significant reason for adopting this approach is: as "The mixed method approach is appropriate as RFID research is still in its infancy" stage therefore, "a combination of methodological techniques assists in exploring the RFID adoption phenomenon more fully" (Brown and Russell 2007, p. 252).

Therefore, to study RFID adoption, theoretical factors and variables are needed to borrow from other established adoption studies namely innovation adoption, technology adoption, IS/IT adoption researches. However, it will be quite optimistic assumption that those factors can effectively be utilized to deal with RFID adoption in a very dissimilar environment; in the livestock field. Therefore, the widely acceptable factors need to be verified/ contextualized by a group of representatives of livestock farms. Moreover, the exploration of new factors is also not unlikely. The qualitative study meant to perform this role. 
Similarly, the rational for a survey is also very strong for this study. The adoption diffusion behavior of a livestock-farm is a very subjective issue because each farm has its own perceptions, perspective, expectation, and experience. The rationales, motivations, and incentives to adopt and use RFID of one farm might be different from others. Further, there are a multitude parallel factors that contribute to such decision. Thus, conducting field study interviewing a number of farms that can represent the whole industry is time consuming, effort-driven, and not much an effective way. Furthermore, qualitative approaches can generate a social desirability bias. Instead, a nation-wide survey could perform this job in an efficient manner.

Since this research provides evidence of hypotheses, quantifiable measures of variables, hypotheses testing, and the drawing of inferences about a phenomenon from the sample to a stated population, the positivist paradigm has been considered to be appropriate for this research.

\section{Qualitative Field Study}

\subsection{Sampling}

The number of cases suggested by researchers varies. Some researchers suggest an openended number of cases while others recommend a restricted range. The most appropriate range falls between four and eight (Eisenhardt 1989). This study approached eight livestock-farms for investigations. As with many qualitative studies, we employed purposive sampling rather than random sampling (Corbin and Strauss 2008). The farms were chosen from the short-listed farms, prepared by discussion with several officials of Department of Agriculture and Food, Western Australia (DAFWA). The shortlisted farms were chosen, by considering their diversity, interest, and contribution to the livestock community. More family-owned small-farms have been considered because small farms are recognized as the major sector in the Australian livestock industry (Green 2009). Table 1 summarizes the profiles of each organization. In this study, farmer is defined as the decision-making unit of a livestock farm: for a corporate farm it is the 'manager' whereas in a family-owned-and-operated farm it is the "Owner-Manager". In both cases, s/he is usually responsible for the day-to-day operation of the farming business and may own or have a share in the business (Hooper 2010).

Table 1. Profile of the organizations

\begin{tabular}{llll}
\hline Farm ID & Farm type & Area (hectare) & No. of livestock \\
\hline A & F & 352 & 560 cattle \\
B & F & 44 & 200 cattle, 40 sheep \\
C & C & 20,000 & 12,000 cattle and 7,000 sheep \\
D & F & 300 & 400 cattle \\
E & F & 2,800 & 1,000 cattle, 130 sheep \\
F & C & 10,000 & 8,000 cattle \\
G & F & 1,000 & 800 cattle \\
H & F & 1,114 & 7,000 sheep \\
\hline
\end{tabular}

F: Family-owned-operated, C: Corporate 


\subsection{Data Collection}

This study involved face-to-face, one-to-one, infield, and in-person interviews and therefore all farms were within a $300 \mathrm{~km}$ radius of Perth, the capital city of WA. At the beginning of each interview the participant was given a brief outline of the research purpose, together with the ethical issues. The average interview time was around one hour. Reliability was achieved by using the same interview-protocol for each case. The interviewer inserted the questions into the conversation and prompted when needed. With the permission of the participants, the interviews were recorded.

\subsection{Data Analysis}

A modus operandi approach (Scriven 1976), which consists of triangulating independent indices, has been adopted for this study, which is achieved by analyzing the same factor from multiple instances. The analysis also involved browsing the information repositories to find the participants' views on similar issues. Interestingly, some of the comments (during the interview) of two respondents came up as contradicting to their previous comments on the same issues, published in public media. In those cases, the participant was called again to make his/her position clear. During developing the variables from the interviews, this study followed both the theoretical replication as well as the literal replication (Chan and Ngai 2007). Theoretical replication was made by contrasting cases between respondents; while literal replication occurred where the cases were obtained from their similarities. Using NVivo8, coding the interviews word-by-word, a number of free nodes were developed by naming each segment of data with a label. Each free node summarized and accounted for each concept about the data. Later, tree nodes were developed. Each tree node became a prospective construct, which consisted of a set of relevant free nodes with a similar concept.

\section{$5 \quad$ Findings and Hypotheses Development}

\subsection{External Pressure}

External pressure is the combination of a few types of pressures which are discussed in the following sections. From the analysis it is found that every farmer in Australia experienced at least one kind of pressure which drove them to adopt RFID. Without having such pressure, most of the farmers would not have implemented RFID in their farming.

\subsubsection{Government Pressure}

It is evident that the regulative pressure from the government made many farmers to adopt RFID, as four (A, B, E, and G) out of eight farms are directly influenced by government legislation and adopted RFID. They all are unanimous to say "I just had to do it" or "...would not go for this system if it were not mandatory". Farm C, however, felt "genuine push" by Department of Food, Western Australia (DAFWA) "for everyone to move in this way" and "a heavily saturated awareness program", and does not consider the "push" as a 'pressure'. On the contrary, RFID adoption in farm $\mathrm{D}$ and $\mathrm{F}$ was not influenced by government pressure as they found it as a "voluntary 
activity" and "commercial advantage", respectively; but agree that the legislation worked as a catalyst.

Based on the analysis, we assume that government pressure is one of the most important driving factors for RFID adoption in WA livestock industry. Therefore, the proposition is:

\section{H1: Greater government pressure will lead to greater RFID adoption.}

\subsubsection{Market Pressure}

The analysis found that the terms competitive pressure, competition, market demand, consumer demand and so on are generally considered, by the farms, as market pressure. They emphasize that food safety and product integrity are becoming nonnegotiable requirements for food commodities in all Australian domestic and export markets. Half of the interviewed farms in this study, however, do not find much pressure from the market while other half do. Farms those are supplying their livestock and meat products to only the local markets do not feel any market pressure for RFIDbased animal identification system whatsoever. However, lately there is an emerging market preference, though not the pressure, for lifetime traceable beef; "Buyers are beginning to show a preference for cattle that can be quickly and accurately traced back to all properties on which they have resided" or "Many of our larger domestic customers are beginning to demand lifetime traceability, particularly the larger supermarket-chains".

Farms like D, F, and $\mathrm{H}$ find the RFID-based animal traceability system as a prerequisite to do business with the EU, Korean, and Japanese market, and those markets are absolutely rigid about the identification and other requirements. Farm $\mathrm{C}$, therefore, does care RFID system because of the customer demand.

.... there is always competitive pressure. You have the competing organizations pushing their products with better than the other one. Therefore, if you have got this sort of traceability in place, it would give your product a push in the competitive market for a better position (Farm C).

Sheep farmers perceive that, by the means of individual sheep-data, competitors can entertain the customers with accurate data and customized product which insists them to adopt RFID in their sheep management operations. However, as because the market pressure has come up as an important factor; this study assumes a contribution from market pressure per se towards RFID adoption.

\section{H2: Greater market pressure will lead to greater RFID adoption.}

\subsubsection{Cognitive Pressure}

A clear difference between mimetic and normative pressures is missing by the respondents, rather it is mingled; this pressure is termed as 'cognitive pressure' (Lawrence et al. 2001). Cognitive pressure comes from the farms' cognition, which is mediated by the external factors, which influences their adoption decision. Sheep farmers, particularly, perceive that the other farmers who adopted RFID for their sheep management system are getting operational efficiency as they can manage sheep individually, not as a flock, which enables improved decision-taking. It is also found that a farm may consider RFID as a means of 'image' or 'prestige'. Farm C 
stated that one of the reasons to adopt RFID was to "take a leadership role" in their community as "small farms around us expect that they would learn from our experience as some of the new things are too expensive" to be tried by the small farms. Farm H also did "try to be different". As the farm-owner of Farm H holds one of the top positions in livestock association, he realized the cognitive pressure "to prove the RFID efficiencies and make them [other farmers] convinced". The proposition is therefore:

H3: Greater cognitive pressure will lead to greater RFID adoption.

\subsection{External Support}

External support to adopt RFID comes from different sources.

[At the beginning] there was fairly a strong awareness program that was going on. The awareness was made by the agriculture department, government staffs, industry staff...

As mentioned by the respondents, external support comes from various channels including government staffs, suppliers' staffs, and organizations staffs that inspires and make farmers confident to adopt RFID technology.

\subsubsection{Government Support}

Farmers are very satisfied with the supports from the government department. They all agreed that if they get any problems, DAFWA would be the first place to seek assistance from. "The agriculture department is pretty responsive. I am pretty happy with them" (Farm C). Except farm C, all asked for incentives, unanimously. "Without the subsidy, it's a bit of struggle" (Farm B). "The farmers should get subsidized tags and readers" (Farm A). They unanimously supported that government support, on RFID costs in particular, will increase RFID adoption. However, farm C does not agree: "I do not support if the total cost is reimbursed to the farmers because it would send the farmers wrong message. It was the lesson to blow for a management change; that's really came down to". However, Australian government is supporting the livestock industry by taking the expenses of building, maintaining, and developing infrastructure. The basic infrastructure includes identifying the farms uniquely, managing the NLIS database, and providing ICT infrastructure. Interestingly it is found that the then infrastructure did not have any influence in RFID adoption rather the RFID adoption has a positive influence in upgrading the infrastructure because government needed to provide internet facility, for example, to upload the data from the farm-site to the MLA-site. In fact, because of the growing pressure, the infrastructure is getting better. "Now, many of them (the farms) have satellite broadband which was actually done by the government in the remote area". However, the continuous existing support from the agriculture department is believed to be satisfactory towards RFID adoption. The proposition, thus, becomes:

\section{H4: Greater government support will lead to greater RFID adoption.}

\subsubsection{Vendor Support}

RFID is introduced, governed, and disseminated mainly by the government agencies. The respondents argued that the vendors have least involvement and influence in 
Australian livestock, particularly in RFID context. However, three of the interviewees received troubleshooting support from the vendors at the initial stage which is now discontinued. It is apparent from the interviews that the providers were much proactive and supportive at the initial stage of RFID introduction and now, may be, have concentrated to other applications. Farmers stated that except for large-scale integration of RFID systems they do not need vendor support, anyway.

\subsubsection{Associative Support}

This study finds a distinctive source of support which can be called as 'union support' or 'association's support' or the 'support from the industry bodies'. It is found that the farmers have different formal associations (through which they bargain with externals and market their products) and informal networks (to share and seek knowledge). The level and frequency of involvement with those networks affects the speed and level of RFID adoption. Six participants do have a regular participation in their associations. However, one interviewee felt that the association is more concentric on general farming issues rather business issues like enhancing the brand image and exploring new international markets. The proposition, thus, becomes:

H5: More support from farming association will lead to greater RFID adoption.

\subsection{Environmental Uncertainty}

In contrast to the literature, this study finds that external uncertainty decreases the rate and level of RFID adoption as farmers do not know how long the demand will be for a RFID-based animal information system. Similarly some farmers are not interested to invest in keeping more information to entertain Japanese and Korean market as they are not certain about the other markets' future intention and timing of such extension of requirements. Instead, they would concentrate on finding new markets with less RFID requirements such as in the Middle East, Lebanon, Dubai, Philippines, and Russia. Moreover, Farm D worries that a better technology may replace the RFID technology which, they think, deters other farms to adopt RFID technology. Thus, the proposition supported is:

H6: Higher environmental uncertainty will decrease the speed and level of RFID adoption.

\section{Proposed Framework for RFID Adoption}

Based on the above analysis and literature review the research model is developed which is presented in Fig. 1. This model proposes that external pressure (consists of government pressure, market pressure, and cognitive pressure), external support (government support, and associative support) positively influence RFID adoption while external uncertainty negatively influences RFID adoption in Australian livestock industry. 


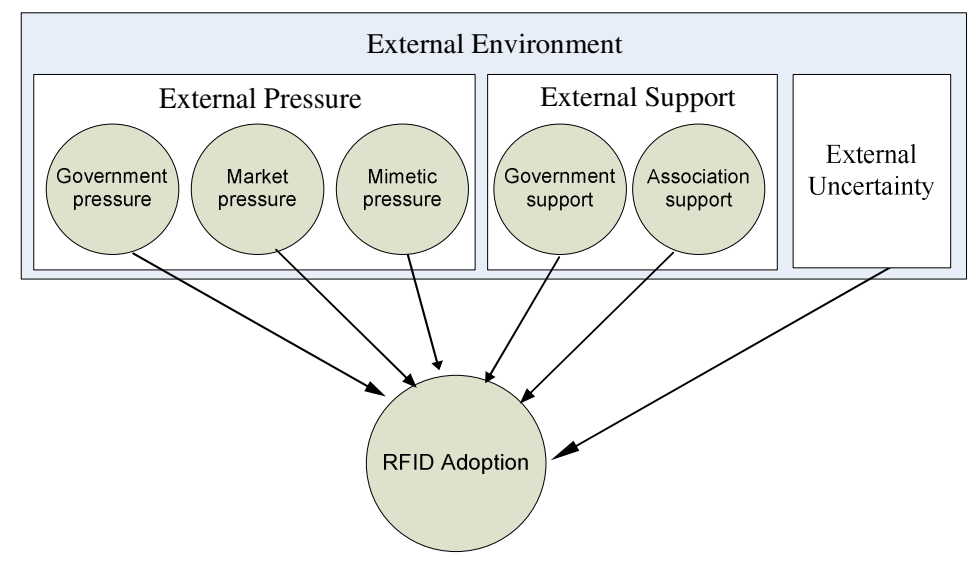

Fig. 1. The proposed framework for environmental effects on RFID adoption

\section{$7 \quad$ Quantitative Study}

\subsection{Sample}

This research struggled badly conducting the survey especially to collect the contacts of the sample. Because of the strong 'privacy' provision with every agencies and farmers' association the researchers found it very hard to collect the information. However, a technique was provided by the DAFWA which retrieves the contact of each farm from an online database. In this data-retrieval process 568 contacts were generated. Later, a contact list of 2,600 WA cattle farms were supplied by the DAFWA. In total, 1,200 farms were invited to participate the survey. The samples were chosen using a random sampling technique. Each paper-based questionnaire provided a temporary URL (web link) so that respondents could alternatively use the online version in Survey Monkey. Moreover, a national agency agreed to attach the equestionnaire with electronic newsletters to its members/subscribers.

To secure the confidence of the respondents they were ensured that their identity could never be detected thus ensuring the privacy and anonymity. For the convenience of the respondents, a stamped and addressed reply-envelope was provided. Unlike other surveys, this survey did not include a 'follow-up' procedure. This was actually not possible; because, the questionnaire did not include any reference-code to check whether a particular respondent replied or not. This was intentionally done to increase the reliability and thus the response rate. Overall, 220 returned surveys were useable. The response rate could not be established; however, the rate is low which is not uncommon for small businesses in Australia (Dawson et al. 2002).

\subsection{Data Examination}

As mentioned earlier, this research was conducted through an online survey as well as through the traditional mail survey. The responses from the mail survey were split into early and late respondents. Also, the online survey-respondents were considered 
as the early respondents. Therefore, the responses were grouped into Wave 1 and Wave 2 sample. 139 responses were in Wave 1 and the rest 81 were in Wave 2. Independent sample Mann-Whitney $U$ Test was performed to test the significant differences between two different waves. The test was performed in terms of gender, highest level of education, and age of the person completing the survey, income of the farm, and one indicator from the research model. The result established that in each instance $\mathrm{z}$-values are not significant at 0.05 level. In other words, the distribution of gender, for example, is same across two different waves of the survey sample, and there was negligible non-response bias between Wave 1 and Wave 2 sample. Therefore, the response for Wave 1 and Wave 2 samples could be combined for data analysis (Quaddus and Hofmeyer 2007). The number of usable responses met the requirement level: 10 times the number of items in the most complex formative construct or the largest number of antecedent constructs leading to an endogenous construct in the research model, as argued by Barclay et al. (1995).

\subsection{Measures}

The six factors described earlier (see Fig. 1) have been measured with great care. The factors were operationalised first from the literature which was further enhanced through the field study. Six-point Likert scale ranging from 'strongly disagree' to 'strongly agree' has been used to measure 22 items while two items (of RFID adoption) were measure with " $<1>, \quad<2>,<3>, \quad<>, \quad<5, \quad<$ more than 5> years/applications" scale.

\subsection{Quantitative Results}

The data gathered from the survey phase were analyzed by partial least squares (PLS)-based structural equation modeling (Barclay et al. 1995). This study used the standard PLS analysis of the individual item reliability, composite reliability, and discriminant validity to assess the adequacy of the measurement model (Barclay et al. 1995; Hulland 1999).

\subsubsection{Assessment of Measurement Properties}

The initial research model consisted of 24 observed variables. As par the PLS procedure (Barclay et al. 1995; Hulland 1999), this model was tested for item reliability, internal consistency, and discriminant validity to assess the measurement adequacy of the model. Referring to Igbaria et al.'s (1995) argument this research adopted the minimum cut-off level of 0.5 for item loading; following this rule, one item was discarded (GS3: 0.1679). The item loadings are detailed in Table 2 with the low loading item marked as ' $a$ '. The revised model with 20 observed variables were again tested using PLS and all item reliabilities exceeded the 0.5 reliability criteria. This result confirms that all items are sufficient to represent their respective construct. The item loadings have not considered for the only formative construct external uncertainty. However, the items were checked with acceptable VIF values and the weight scores. 
Table 2. The item loadings

\begin{tabular}{llll}
\hline & Construct & Item & PLS loading \\
\hline Govt. Pressure & Legislation & GP1 & 0.5092 \\
& Government intervention & GP2 & 0.9999 \\
Market Pressure & Market demand & MP1 & 0.7922 \\
& Trading requirement & MP2 & 0.6697 \\
& Business pressure & MP3 & 0.8647 \\
& Competitive pressure & MP4 & 0.5049 \\
& Competition & MP5 & 0.8193 \\
Cognitive Pressure & Mimetic pressure & CP1 & 0.6091 \\
& Favorability & CP2 & 0.7052 \\
& Normative pressure & CP3 & 0.7829 \\
& Subjective norm & CP4 & 0.5915 \\
Govt. Support & Information service & GS1 & 0.8137 \\
& Infrastructure & GS2 & 0.8160 \\
& Taxation & GS3 & $0.1679^{\mathrm{a}}$ \\
& Training & GS4 & 0.7450 \\
Ass. Support & Demonstration & AS1 & 0.7732 \\
& Publication & AS2 & 0.7152 \\
& Discussion & AS3 & 0.6144 \\
Adoption & Significance & ADP1 & 0.8788 \\
& Duration & ADP2 & 0.5777 \\
& Extent & ADP3 & 0.5161 \\
\hline
\end{tabular}

'a' denotes for discarded item

The Fornell and Larcker's (1981) method was used to evaluate the model for internal consistency (see Table 3). Referring to Table 3, all constructs met the acceptable criterion for composite reliability (CR) (0.7 or more) and AVE (0.5) (Jiang et al. 2002). The highest CR was observed for associative support (0.857) followed by cognitive pressure (0.849) and market pressure (0.848), and the lowest being adoption (0.705). Similarly, the AVE values for every constructs exceeded the recommended value 0.5 , which means that convergent analysis for these constructs is satisfied. The highest value for AVE was experienced by associative support (0.668) and the lowest was by adoption (0.507).

Table 3. Internal Consistency and AVE for the constructs

\begin{tabular}{lll}
\hline Construct & Composite Reliability & AVE \\
\hline Government pressure & 0.715 & 0.592 \\
Market pressure & 0.848 & 0.539 \\
Cognitive pressure & 0.849 & 0.584 \\
Government support & 0.795 & 0.531 \\
Associative support & 0.857 & 0.668 \\
Adoption & 0.705 & 0.507 \\
\hline
\end{tabular}


Table 4 presents the detailed results of discriminant validity test. The square root of AVEs are shown as the diagonal elements and the off-diagonal elements represent the correlations among the latent variables. Table 4 indicates that the square root of AVE is greater than the off-diagonal elements across the row and down the column. The result indicates that all items demonstrate higher loadings in their respective constructs in comparison to their cross loadings in other constructs. Therefore, it confirms that the measurement model has strong discriminant validity at construct level - all the latent variables are different from each other.

Table 4. Correlation of Latent Variables and the Square Root of AVE

\begin{tabular}{lllllll}
\hline & GP & MP & CP & GS & AS & ADP \\
\hline Government pressure (GP) & $\mathbf{0 . 7 6 9}$ & & & & & \\
Market pressure (MP) & 0.127 & $\mathbf{0 . 7 3 4}$ & & & & \\
Cognitive pressure (CP) & 0.097 & 0.656 & $\mathbf{0 . 7 6 4}$ & & & \\
Government support (GS) & 0.199 & 0.363 & 0.465 & $\mathbf{0 . 7 2 9}$ & & \\
Associative support (AS) & 0.155 & 0.310 & 0.422 & 0.654 & $\mathbf{0 . 8 1 7}$ & \\
Adoption (ADP) & 0.118 & 0.580 & 0.519 & 0.432 & 0.299 & $\mathbf{0 . 6 7 6}$ \\
\hline
\end{tabular}

Bold diagonal elements are the square root of AVE

Based on the outcomes as shown in Table 2, 3, and 4, overall result of the measurement model has provided satisfactory empirical support for the reliability, convergent, and discriminant validity. Having established that the measurement model is adequate and sufficient, the next phase of PLS analysis was to analyze the assessment of the structural model. This analysis is presented in the next section.

\subsection{Assessment of the Structural Model}

The score of $\mathrm{R}^{2}$ is $0.425 . \mathrm{R}^{2}$ value can be interpreted in the following way: the model explained $42.5 \%$ of the variance in RFID adoption. Overall findings show that all scores of $\mathrm{R}^{2}$ value satisfy the requirement for the 0.10 cut off value (Quaddus and Hofmeyer 2007).

To provide a clearer picture, Table 5 is presented along with the result of the research hypotheses. As shown in the Table 5, the influence of market pressure $(\mathrm{H} 2)$, cognitive pressure (H3), government support (H4), and external uncertainty (H6) are found to be significant on RFID adoption. However, the influence of government pressure, and associative support on RFID adoption are not supported. 
Table 5. Evaluation of the research hypotheses for the antecedents factors

\begin{tabular}{lllll}
\hline Hypothesis & Link & $\begin{array}{l}\text { Path } \\
\text { Coeff. }\end{array}$ & $t$-value & Result \\
\hline H1 & Govt. Pressure to Adoption & -0.002 & 0.0270 & Not Supported \\
H2 & Market Pressure to Adoption & 0.416 & $6.0263 * * *$ & Supported \\
H3 & Cognitive Pressure to Adoption & 0.125 & $1.6853 *$ & Supported \\
H4 & Govt. Support to Adoption & 0.232 & $2.8306 * * *$ & Supported \\
H5 & Associative Support to Adoption & -0.080 & 1.0826 & Not Supported \\
H6 & Uncertainty to Adoption & 0.142 & $2.5323 * *$ & Supported \\
\hline
\end{tabular}

Significance at $* \mathrm{p}<0.05, * * \mathrm{p}<0.01, * * * \mathrm{p}<0.005$

\section{Discussion and Implications}

This study provides a clearer understanding of the influence of external environmental factors on the adoption of RFID. The contributing environmental factors of RFID adoption are market pressure, cognitive pressure, government support, and external uncertainty.

In general, cattle farmers in Western Australia adopt RFID because of market pressure with the hope that it would give them a competitive-edge in the marketplace. Moreover, the cognitive pressure (particularly in sheep identification) is one of the contributing factors adopting RFID. It is found that government pressure does not have an influence on RFID adoption which is bit surprising in Australian-livestock context. Actually, to comply with the legislation, many of the farms attach RFID tags just immediately before the cattle are moved to another farm ('slap and ship' technique). Technically, this process is not treated as adoption. Hence, the lack of influence of government pressure on RFID adoption is not exceptional.

However, RFID adoption is dependent on government support. For example, for an effective system that ensures lifetime traceability of animals farms need to upload animal information in a central national database which requires unique (farm) identification number, Internet facilities and so on. Without a strong infrastructure of data management the whole initiative might go wrong/ useless. Moreover, a more proactive and aggressive approach from the vendors, by demonstrating RFID projects and providing technical support, would inspire farmers embracing more RFID applications and services. Finally, a positive approach from the farming associations toward RFID technology and thus educating the farmers is invaluable.

This study finds that external uncertainty decreases RFID adoption. Farms informed that there is a lack of consistency on data requirement; markets request for more and different data. To provide a new set of data farms may require making a major change in the RFID system. Therefore, farms that are not certain about the market-requirements are less interested adopting RFID. Some farmers are not interested to invest on keeping more information to entertain Japanese and Korean market, for example, as they are not certain about the other markets' future intention and timing of such extension of requirements. Consequently, this type of uncertainty hinders the RFID adoption as farmers do not know how long the demand for record keeping and how viable it will be. Instead, farms would concentrate on finding new markets 
with less RFID requirements such as in the Middle East, Lebanon, Dubai, Philippines, and Russia (Rees 2008).

The findings from this study are of considerable significance for RFID adoption, particularly for those countries which have a plan or are under pressure to apply RFID technology to identify objects. They may consider that supporting farms is more useful than exercising pressure. Government pressure sometimes develops a negative image, and negative perceptions about the technology. Moreover, in lieu of relying on other supports (e.g., vendors, associations, networks) government should take the leadership role and offer every-possible supports to the prospective adopters, and adopters; even after the adoption takes place. Furthermore, the government as well as technology providers must realize that (hence make the farms to realize) though the 'slap and ship' technique conforms the law but does not guarantee the optimum return. To get the best of the technology and cost effective, farms need to use RFID on every possible farm operations; mere adoption at the last minute is just underutilizing the technology and its associated costs. Hence, the government agencies can prepare their task-list realizing the outcomes of this study. For example, they may use 'incentive' as the main support for a quick adoption of RFID.

As a theoretical contribution, this paper is the first initiative investigating solely the environmental factors responsible for RFID adoption. This study presents a systematic presentation of those factors. The concept of 'cognitive pressure' is studied by the researches in individual-adoption but not in organizational perspective. This study proposes to use this term in organizational adoption research which could be viewed as the integration of two concepts from institutional theory: mimetic pressure and normative pressure. The survey result supports this presumption. Moreover, the field study in this research finds that, the associative support (farmers' associations and the relationship among other farmers) is very important for RFID adoption; which is not discussed in the literature with due importance. Finally, relevant organizations and bodies could pay attention reducing external uncertainty which would increase RFID adoption. One of the solutions of reducing many uncertainties, in RFID context, is setting and practicing a global standardization.

\section{$9 \quad$ Future Research and Conclusion}

This study presents the significance of external environmental factors on RFID adoption. The factors have been explored from an extensive literature review which were confirmed and contextualized from a field study. The contextualized factors, then, have been examined by a quantitative survey data. Following the 'mixed method' research approach this study is the first of its kind detailing the factors from external environment. The results and implications support that this research has the potential to be applied in other similar studies. However, future studies could integrate this current model with technological and organizational factors, and be tested to find the effects of those factors on RFID adoption. Also, testing this model separately with adopters and yet-to-be adopters would be worthwhile and interesting. 


\section{References}

Bandura, A.: Social Cognitive Theory of mass communication. Media Psychology 3(3), 265-299 (2001)

Bansal, R.: Coming soon to a Wal-Mart near you. IEEE Antenna and Propagation Magazine 45(6), 105-106 (2003)

Barclay, D., Higgins, C., Thomson, R.: The partial least squares (PLS) approach to causal modeling: Personal computer adoption and use as an illustration. Technology Studies 2(2), 285-309 (1995)

Brown, I., Russell, J.: Radio frequency identification technology: An exploratory study on adoption in the South African retail sector. International Journal of Information Management 27(4), 250-265 (2007)

Chan, S.C.H., Ngai, E.W.T.: A qualitative study of information technology adoption: how ten organizations adopted Web-based training. Information Systems Journal 17(3), 289-315 (2007)

Corbin, J.M., Strauss, A.L.: Basics of qualitative research: Techniques and procedures for developing grounded theory, 3rd edn. Sage, California (2008)

Dawson, S., Breen, J., Satyen, L.: The ethical outlook of Micro business operators. Journal of Small Business Management 40(4), 302-313 (2002)

Eisenhardt, K.M.: Building Theories from Case Study Research. The Academy of Management Review 14(4), 532-550 (1989)

Fornell, C., Larcker, D.F.: Evaluating Structural Equation Models with unobservable variables and measurement error. Journal of Marketing Research 18(1), 39-50 (1981)

Garry, M.: Albertsons launches RFID program. Supermarket News (2004)

Gatignon, H., Robertson, T.: Technology diffusion: an empirical test of competitive effects. Journal of Marketing 53, 35-49 (1989)

Gibbs, J.L., Kraemer, K.L.: A cross-country investigation of the determinants of scope of Ecommerce use: An institutional approach. Electronic Markets 14(2), 124-137 (2004)

Green, B.: Implementation of the National Livestock Identification System (Cattle) Business Plan in Western Australia (2005-2008), Department of Agriculture and Food, WA (2009)

Hooper, S.: Australian Beef, Australian Bureau of Agricultural and Resource Economics (ABARE) (2010), http://www.abare.gov.au/publications_html/lives tock/livestock_10/beef_10_1.pdf

Hossain, M.A., Quaddus, M.: The Adoption and Continued Usage Intention of RFID: An Integrated Framework. Information Technology \& People 24(3), 236-256 (2011)

Huyskens, C., Loebbecke, C.: RFID Adoption: Theoretical Concepts and their Practical Application in Fashion. In: Organizational Dynamics of Technology-Based Innovation: Diversifying the Research Agenda, pp. 345-361. Springer, Boston (2007)

Hulland, J.: Use of partial least squares (PLS) in strategic management research: a review of four recent studies. Strategic Management Journal 20, 195-204 (1999)

Iacovou, C.L., Benbasat, I., Dexter, A.S.: Electronic Data Interchange and Small Organizations: Adoption and Impact of Technology. MIS Quarterly 19(4), 465-485 (1995)

Igbaria, M., Guimaraes, T., Davis, G.B.: Testing the Determinants of Microcomputer Usage via a Structural Equation Model. Journal of Management Information Systems 11(4), 87-114 (1995)

Jiang, J.J., Klein, G., Carr, C.L.: Measuring information system service quality: SERVQUAL from the other side. MIS Quarterly 26(2), 145-166 (2002)

Jones, M.A., Wyld, D.C., Totten, J.W.: The adoption of RFID technology in the retail supply chain. The Coastal Business Journal 4(1), 29-42 (2005) 
Kimberly, J.R., Evanisko, M.J.: An integrated model of information systems adoption in small businesses. Academy of Management Journal 24(4), 689-713 (1981)

Lawrence, T.B., Winn, M.I., Jennings, P.D.: The temporal dynamics of institutionalization. The Academy of Management Review 26(4), 624-644 (2001)

Lee, C., Shim, J.: An exploratory study of radio frequency identification (RFID) adoption in the healthcare industry. European Journal of Information Systems 16(6), 712-724 (2007)

Li, S., Visich, J.K.: Radio frequency identification: supply chain impact and implementation challenges. International Journal of Integrated Supply Management 2(4), 407-424 (2006)

Lin, C.-Y.: An Empirical Study on Organizational Determinants of RFID Adoption in the Logistics Industry. Journal of Technology Management \& Innovation 4(1), 1-7 (2009)

Lin, C.-Y., Ho, Y.-H.: An Empirical Study on the Adoption of RFID Technology for Logistics Service Providers in China. International Business Research 2(1), 23-36 (2009)

Luo, Z., Tan, Z., Ni, Z., Yen, B.: Analysis of RFID in China. In: Proceedings of IEEE International Conference on e-Business Engineering, pp. 315-318 (2007)

Matta, V., Moberg, C.: Defining the Antecedents for Adoption of RFID in the Supply Chain. Issues in Information Systems 8(2), 449-454 (2007)

Moberg, C.R., Cutler, B.D., Gross, A., Speh, T.W.: Identifying antecedents of information exchange within supply chains. International Journal of Physical Distribution \& Logistics Management 32(9), 755-770 (2002)

Nolz, A.: Setting the RFID standard. In: Beef Magazine. Penton Media Inc. (2008)

Oxley, J.E.: Institutional environment and the mechanisms of governance: the impact of intellectual property protection on the structure of inter-firm alliances. Journal of Economic Behavior \& Organization 38(3), 283-309 (1999)

Patterson, K., Grimm, C., Corsi, T.: Adopting New Technologies for Supply Chain Management. Transportation Research (Part E): Logistics and Transportation Review 39(2), 95-121 (2003)

Poirier, C.C., McCollum, D.: RFID Strategic Implementation and ROI: a practical roadmap to success,.J. ROSS Publishing (2006)

Quaddus, M., Hofmeyer, G.: An investigation into the factors influencing the adoption of B2B trading exchanges in small business. European Journal of Information Systems 16, 202-215 (2007)

Rees, T.: Globalisation impacts the Australian meat industry. In: Meat International, Meat International (2008)

Roberti, M.: Wal-Mart Spells Out RFID Vision. RFID Journal (2003), http: / /www.rfidjournal.com/article/purchase/463

Rogers, E.M.: Diffusion of Innovation. Free Press, New York (1995)

Schmitt, P., Michahelles, F.: Status of RFID/EPC Adoption. In: Auto-ID Labs White Paper, Auto-ID Labs, 1-41 (2009)

Scott, W.R.: Institutions and Organizations. Sage Publications, CA (2001)

Scriven, M.: Maximizing the power of causal investigations: The modus operandi method. In: Evaluation Studies Review Annual, pp. 101-118. Sage Publications, CA (1976)

Scupola, A.: The adoption of Internet commerce by SMEs in the South of Italy: An environmental, technological and organizational perspective. Journal of Global Information Technology Management 6(1), 51-71 (2003)

Semple, K.: NLIS: On-farm Benefits. Agriculture Notes, Department of Primary Industries, Victoria, Australia (2007)

Sharma, A., Citurs, A.: Radio Frequency Identification (RFID) adoption drivers: a radical innovation adoption process. In: Proceedings of Americas Conference on Information Systems (AMCIS), NE, USA (2005) 
Sharma, A., Citurs, A., Konsynski, B.: Strategic and institutional perspectives in the adoption and early integration of Radio Frequency Identification (RFID). In: Proceedings of the 40th Hawaii International Conference on System Sciences (2007)

Shih, D., Chiu, Y., Chang, S., Yen, D.: An empirical study of factors affecting RFID's adoption in Taiwan. Journal of Global Information Management 16(2), 58-80 (2008)

Tashakkori, A., Teddlie, C.: Mixed methodology: Combining qualitative and quantitative approaches. Sage Publications, Inc., California (1998)

Teo, H., Wei, K., Benbasat, I.: Predicting intention to adopt interorganizational linkages: An institutional perspective. MIS Quarterly 27(1), 19-49 (2003)

Tornatzky, L.G., Fleischer, M.: The process of technological innovation. Lexington Books, Lexington (1990)

Wen, L., Zailani, S., Fernando, Y.: Determinants of RFID Adoption in Supply Chain among Manufacturing Companies in China: A Discriminant Analysis. Journal of Technology Management \& Innovation 4(1), 22-32 (2009)

Whitaker, J., Mithas, S., Krishnan, M.: A field study of RFID deployment and return expectations. Production and Operations Management 16(5), 599-612 (2007)

Zhu, K., Kraemer, K., Xu, S.: Electronic Business Adoption by European Firms: A CrossCountry Assessment of the Facilitators and Inhibitors. European Journal of Information Systems 12(4), 251-268 (2003) 